\title{
Green Chemistry Approach to the Synthesis of Biscoumarins from 4-Hydroxycoumarin
}

\author{
Mirjana Lončar, ${ }^{1}$ (1) Marija Kovač, ${ }^{2}$ (i) Maja Molnar ${ }^{1, *}$
}

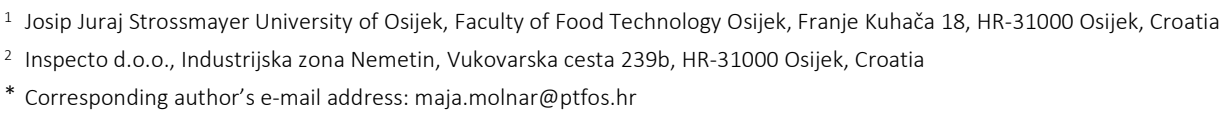

RECEIVED: May 28, 2020 \REVISED: July 3, $2020 \star$ ACCEPTED: July 7, 2020

Abstract: Numerous biological and pharmacological properties of coumarins have designated them as significant synthetic target in many fields. Biscoumarins are considered as an important class of coumarin derivatives that show remarkable pharmacological properties. Therefore, development of the efficient new methods for their synthesis, based on green methodology, would be of a great importance in medicinal and pharmaceutical chemistry.

In this work, the ultrasound and microwave assisted synthesis of biscoumarins, starting from corresponding aldehydes and 4-hydroxycoumarin is reported. Molecular iodine was used as an efficient and inexpensive catalyst for a simple synthesis, to obtain excellent yields using ethanol as a solvent. It was found that $10 \%(n / n)$ of molecular iodine catalyzes biscoumarin synthesis in high yields (80-94 \%) and in short reaction times, using both ultrasound, as well as microwave promoted conditions. Furthermore, when those two methods are compared, ultrasound promoted reactions were proven to be more suitable for this kind of reaction.

Keywords: 4-hydroxycoumarin, biscoumarins, microwave assisted synthesis, ultrasound assisted synthesis.

\section{INTRODUCTION}

C OUMARINS are aromatic, heterocyclic benzopyrone compounds, widely distributed in the plant kingdom as well as synthesized by many researchers these days, which have been extensively investigated in many scientific fields ${ }^{[1]}$ They possess many biological properties, that primarily depend on their structure $\mathrm{e}^{[2,3]}$ and some of those biological activities include antimicrobial, $[4,5]$ anti-inflammatory, ${ }^{[6]}$ anti-HIV, ${ }^{[7]}$ anti-depressive, ${ }^{[8]}$ antioxidant, ${ }^{[9,10]}$ anticoagulant, ${ }^{[11]}$ anticancer, ${ }^{[12,13]}$ antiviral, ${ }^{[14,15]}$ antimycobacterial, ${ }^{[16]}$ and antiasthmatic. ${ }^{[17]}$ Furthermore, coumarins possess significant optical properties, thus being used in dispersed fluorescent and laser dyes, fluorescent probes, polymers, insecticides and in optical brighteners. ${ }^{[1,18]}$ Due to their biological and pharmacological properties, coumarins are used worldwide as a basic structural unit in drug production. One of the often investigated groups of coumarin derivatives are their bis-analogues, so called biscoumarins, dimers of 4-hydroxycoumarin, which are proven to act as anticoagulants, ${ }^{[19,20]}$ and antiseptics. ${ }^{[21]}$ In addition to these properties, Khan and co-workers ${ }^{[22]}$ found that biscoumarins could also act as urease inhibitors, which is important in the treatment of infectious diseases caused by urease producing bacteria. Dicoumarol, a naturally occurring biscoumarin originating from plants or fungi, is recognized as an anticoagulant, which decreases the metastases in experimental animals and acts as a vitamin $\mathrm{K}$ depleter, ${ }^{[24]}$ while in biochemical experiments is used as an reductase inhibitor. ${ }^{[23]}$ The literature overview reveals the growing interest in biscoumarin synthesis, which raises the question of the environmental impact of such chemical processes.

Biscoumarins are commonly prepared through Knovenagel reactions of 4-hydroxycoumarin with different aldehydes (Scheme S1), utilizing a wide range of different catalysts, solvents, and reaction conditions, all resulting in different reaction times and different yields. ${ }^{[23]}$

So far, biscoumarins were synthesized using ultrasound irradiation, ${ }^{[25,26]}$ microwave irradiation, $[27,28]$ different thermal conditions (reflux, heating, room 
temperature), ${ }^{[2,29,30,31]}$ using catalysts such as: solid catalysts, ${ }^{[32]}$ ionic liquids. ${ }^{[33]}$ nanoparticles, ${ }^{[34]}$ phasetransfer catalysts, ${ }^{[35]}$ Lewis acids, ${ }^{[30,36]}$ heteropoly acids, ${ }^{[37]}$ and nanocomposites. ${ }^{[38]}$ Majority of these methods have certain disadvantages, such as an extensive use of expensive and/or toxic organic solvents, difficult work-up procedure, or harsh reaction conditions, resulting in low product yields.

Tabatabaeian and co-workers ${ }^{[29]}$ performed the synthesis of biscoumarins using $\mathrm{Ru}$ grafted zeolite $\beta$ (Ru@imine-Z) catalyst. The optimal amount of the catalyst was $10 \%(\mathrm{~m} / \mathrm{m})$ when the reaction was carried out under reflux conditions. They also studied the effect of solvent, using different solvents such as ethanol, methanol, acetonitrile, tetrahydrofuran and dichloromethane, at different reflux temperatures, and ethanol was chosen as the best solvent for this reaction. Moreover, they prepared a series of biscoumarins under reflux condition and also under ultrasound irradiation. The results confirmed that ultrasound irradiation leads to the final products in shorter reaction times. ${ }^{[29]}$

Although much work has been done on the synthesis of biscoumarins under classical conditions, the use of green methods such as ultrasound irradiation or microwave dielectric heating for their synthesis is relatively rare. Therefore, in this work we investigated the catalytic property of molecular iodine, as an easy available and inexpensive catalyst, for Knoevenagel condensation of 4-hydroxycoumarin and different aromatic aldehydes, in ultrasound and microwave promoted reactions. These two methods, among others, are often characterized as green synthetic methods.

Nowadays a green chemistry approaches are favorable both in research as well as industry, since there is the growing consciousness of environmental issues and increasing importance to reduce the usage of dangerous chemicals, that have a direct risk both to the pollution and human health.

\section{EXPERIMENTAL}

All chemicals used in the synthesis of desired compounds were purchased from commercial suppliers. Microwave synthesis was performed in Milestone flexiWAVE (Milestone Srl, Sorisole (BG), Italy) microwave system, equipped with rotating carousel with 15 positions for PTFE high-pressure vessels. Ultrasound synthesis was performed in ultrasonic bath (BANDELIN GmbH \& Co, DT $510 \mathrm{H}$ ).

Mass spectra were recorded on Shimadzu LCMS2020, Japan under flow injection analysis with flow of $0.5 \mathrm{~mL} \mathrm{~min}{ }^{-1}$ ( $50 \%$ formic acid ( $0.1 \%$ ) and $50 \%$ acetonitrile) and performed in positive and negative mode. NMR spectra were recorded on Bruker Avance $600 \mathrm{MHz} N M R$
Spectrometer (Bruker Biospin GmbH, Rheinstetten, Germany) at $293 \mathrm{~K}$ with DMSO-d6 as a solvent and tetramethylsilane (TMS) as an internal standard.

Melting points were measured on Melting point determination apparatus IA9100 (Cole-Parmer Ltd.). Thinlayer chromatography was performed with fluorescent silica gel plates F254 (Merck, Darmstadt, Germany), under UV (254 and $365 \mathrm{~nm}$ ) light, with benzene/acetone/acetic acid $(8: 1: 1, v / v)$ as a solvent.

\section{General Procedure for the Synthesis of Biscoumarins $2 a-i$ using Ultrasound Irradiation}

An aromatic aldehyde $(2.5 \mathrm{mmol})$ and 4-hydroxycoumarin $(5.0 \mathrm{mmol}$ ) were taken in $25.0 \mathrm{~mL}$ round bottom flask and dissolved in a minimum amount of ethanol $(5.0 \mathrm{~mL})$. Than molecular iodine $(10 \%(n / n))$ was added. The mixture was irradiated by ultrasound in the water bath for appropriate time $\left(30 \mathrm{~min}\right.$ ) at $50^{\circ} \mathrm{C}$. After a completion of the reaction monitored by TLC, the solid product, which precipitated out as an insoluble residue, was filtered, washed with water and dried under vacuum. The crude product was purified by washing with the appropriate solvent (methanol or ethanol).

\section{General Procedure for the Synthesis of Biscoumarins 2a-i using Microwave Irradiation}

An aromatic aldehyde $(2.5 \mathrm{mmol})$ and 4-hydroxycoumarin $(5.0 \mathrm{mmol})$ were mixed together in a minimum amount of ethanol EtOH $(10.0 \mathrm{~mL})$ and subjected to microwaves at $100{ }^{\circ} \mathrm{C}$ for corresponding time (90 $\mathrm{min}$ in total). After completion of the reaction monitored by TLC, the mixture was poured over the water and a crude product was separated by filtration.

Characterization of products (yields, Rf values, melting points, $1 \mathrm{H}$ and $13 \mathrm{C} \mathrm{NMR} \mathrm{data)} \mathrm{are} \mathrm{depicted} \mathrm{in} \mathrm{the}$ supplementary material.

\section{RESULTS AND DISCUSSION}

For the synthesis of biscoumarins (2a-2i), a range of aldehydes (a-i, $2.5 \mathrm{mmol})$ were condensed with 4-hydroxycoumarin (1, $5.0 \mathrm{mmol}$ ) (Scheme S2). The same reactions were carried out by applying two methods, ultrasound and microwave irradiation in the presence of ethanol as a solvent and using cheap, readily available molecular iodine in a catalytic amount $(10 \% n / n)$. Reactions were monitored periodically by thin-layer chromatography (TLC, benzene/acetone/acetic acid 8:1:1 v/v) and when completed, desired products were precipitated with water and washed with corresponding solvent (ethanol or methanol). 
All compounds were characterized by melting points, $R_{\mathrm{f}},{ }^{1} \mathrm{H}$ and ${ }^{13} \mathrm{C}$ NMR. For known compounds, melting points were compared to the literature and found to match, as described in the Experimental section. ${ }^{1} \mathrm{H}$ NMR spectra reveals the characteristic peaks as follows: proton peak shift for $-\mathrm{CH}-$ at $6.14-6.35 \mathrm{ppm}$, aromatic protons shifts from 6.36-8.06, and peaks characteristic for different aromatic substituents, such as $-\mathrm{OCH}_{3}$ protons shifts at 3.49-3.70 ppm (see Supplementary material for spectra). All reactions were carried out both under ultrasound and microwave conditions and in the presence of molecular iodine as a catalyst. When compared, they gave different product yields and required significantly different reaction times. Namely, higher yields of the desired products were obtained by the ultrasound-assisted procedure (Table S1). In addition, the final products were obtained much faster by ultrasound assisted synthesis ( $30 \mathrm{~min}$ ) compared to the microwave assisted synthesis (90 $\mathrm{min}$ ). Therefore, the ultrasound assisted synthesis proved to be better than the microwave assisted synthesis. All the products were crystalline crude products.

When compared to the literature procedure, all the researches mentioned in this paper started the synthesis of biscoumarins using 4-hydroxycoumarin and corresponding aldehydes. Kiyani and co-workers ${ }^{[32]}$ performed the synthesis of biscoumarins using solid catalyst, phthalimide- $N$-sulfonic acid (PISA). They also studied the effect of the solvents, such as water, toluene, dichloromethane, diethyl ether and ethanol and a mixture of ethanol:water $(1: 1)$, as well as solvent-free conditions. According to the results, the ethanol:water mixture at $80^{\circ} \mathrm{C}$ and $10 \%(n / n)$ of PISA were found to be the optimal reaction conditions for these reactions. Under these conditions, they obtained compounds $\mathbf{2 a}, \mathbf{2} \mathbf{c}$, and $\mathbf{2} \mathbf{i}$ in the range of $25-60$ minutes with the yields from 88 to $96 \%$, whereas the scope of our results using ultrasound-assisted procedure were between 81 and $94 \%$ yields in 30 minutes. Al-Kadasi and Nazeruddin ${ }^{[25]}$ performed a catalyst-free synthesis of biscoumarins in water media by ultrasound irradiation at room temperature. They acquired compound $\mathbf{2 g}$ in 15 minutes and in $85 \%$ yield, whereas we acquired the same product in 30 minutes by ultrasound assisted synthesis with $94 \%$ yield. Furthermore, Završnik and co-workers ${ }^{[2]}$ carried out the synthesis of biscoumarins under reflux for $24 \mathrm{~h}$ in ethanol as a reaction media. Under such conditions, they obtained compounds $\mathbf{2 b}, \mathbf{2 c}, \mathbf{2} \mathbf{h}$ and $\mathbf{2} \mathbf{i}$ with yields in range from $\mathbf{7 2}$ to $84 \%$, while our research by the ultrasound-assisted procedure resulted in yields ranging from 81 to $84 \%$ and in considerably shorter time (30 min).

Over and above, Sahar and co-workers ${ }^{[31]}$ performed synthesis of biscoumarins in ethanol and in the presence of few drops of piperidine/ $N$-methylmorpholine. Reactions were carried out by stirring during $24-48 \mathrm{~h}$ at room temperature. They obtained compounds $\mathbf{2 a}, \mathbf{2} \mathbf{d}$ and $\mathbf{2} \mathbf{f}$ with yields in range from 38 to $95 \%$, whereas we obtained the same product in 30 minutes by ultrasound assisted synthesis with yields from 86 to $94 \%$.

\section{CONCLUSIONS}

Biscoumarins have been conveniently prepared with an easy work-up, milder conditions, higher yields of the desired products and shorter reaction time under ultrasound-assisted synthesis, compared to the microwave assisted synthesis. This procedure that includes the usage of a molecular iodine as a catalyst is simple, efficient, inexpensive and ecofriendly method in biscoumarin synthesis. Our work gave higher yields of many derivatives in shorter times, when compared to the literature results. Since biscoumarins are a subject of many different biological investigations, our procedure facilitates their synthesis.

Acknowledgment. This work has been supported in part by Croatian Science Foundation under the project "Green Technologies in Synthesis of Heterocyclic compounds" (UIP2017-05-6593).

Supplementary Information. Supporting information to the paper is attached to the electronic version of the article at: https://doi.org/10.5562/cca3643.

PDF files with attached documents are best viewed with Adobe Acrobat Reader which is free and can be downloaded from Adobe's web site.

\section{REFERENCES}

[1] F. G. Medina, J. G. Marrero, M. Macías-Alonso, M. C. González, I. Córdova-Guerrero, A. G. Teissier García, S. Osegueda-Robles, Nat. Prod. Rep. 2015, 32, 14721507. https://doi.org/10.1039/c4np00162a

[2] D. Završnik, S. Muratović, D. Makuc, J. Plavec, M. Cetina, A. Nagl, E. De Clercq, J. Balzarini, M. Mintas, Molecules 2011, 16, 6023-6040.

https://doi.org/10.3390/molecules16076023

[3] Mayank, A. Singh, N. Kaur, N. Garg, N. Singh, Comput. Biol. Chem. 2019, 83, 107104.

https://doi.org/10.1016/j.compbiolchem.2019.107104

[4] Y. K. Al-Majedy, A. A. H. Kadhum, A. A. Al-Amiery, A. B. Mohamad, Syst. Rev. Pharm. 2017, 8, 62-70. https://doi.org/10.5530/srp.2017.1.11

[5] M. M. Abdou, Arabian J. Chem. 2014, 10, S3664S3675. https://doi.org/10.1016/j.arabjc.2014.04.005

[6] L. Z. Chen, W. W. Sun, L. Bo, J. Q. Wang, C. Xiu, W. J. Tang, J. B. Shi, H. P. Zhou, X. H. Liu, Eur. J. Med. Chem. 2017, 138, 170-181. https://doi.org/10.1016/j.ejmech.2017.06.044 
[7] Y.-P. Liu, G. Yan, Y.-T. Xie, T.-C. Lin, W. Zhang, J. Li, Y.-J. Wu, J.-Y. Zhou, Y.-H. Fu, Bioorg. Chem. 2020, 103699. https://doi.org/10.1016/j.bioorg.2020.103699

[8] K. V. Sashidhara, A. Kumar, M. Chatterjee, K. B. Rao, S. Singh, A. K. Verma, G. Palit, Bioorg. Med. Chem. Lett. 2011, 21, 1937-1941.

https://doi.org/10.1016/j.bmcl.2011.02.040

[9] A. Witaicenis, L. N. Seito, A. da Silveira Chagas, L. D. de Almeida, A. C. Luchini, P. Rodrigues-Orsi, S. H. Cestari, L. C. Di Stasi, Phytomedicine 2014, 21, 240-246. https://doi.org/10.1016/j.phymed.2013.09.001

[10] Y. Bai, D. Li, T. Zhou, N. Qin, Z. Li, Z. Yu, H. Hua, J. Funct. Foods. 2016, 20, 453-462. https://doi.org/10.1016/j.jff.2015.11.018

[11] S. Akoudad, S. K. L. Darweesh, M. J. G. Leening, P. J. Koudstaal, A. Hofman, A. van der Lugt, B. H. Stricker, M. A. Ikram, M. W. Vernooij, Stroke 2014, 45, 34363439. https://doi.org/10.1161/strokeaha.114.007112

[12] M. A. I. Salem, M. I. Marzouk, A. M. El-Kazak, Molecules 2016, 21, 249.

https://doi.org/10.3390/molecules21020249

[13] S. Emami, S. Dadashpour, Eur. J. Med. Chem. 2015, 102, 611-630.

https://doi.org/10.1016/j.ejmech.2015.08.033

[14] S. Mishra, A. Pandey, S. Manvati, Heliyon 2020, 6, e03217.

https://doi.org/10.1016/j.heliyon.2020.e03217

[15] M. Z. Hassan, H. Osman, M. A. Ali, M. J. Ashan, Eur. J. Med. Chem. 2016, 123, 236-255. https://doi.org/10.1016/j.ejmech.2016.07.056

[16] R. S. Keri, B. S. Sasidhar, B. M. Nagaraja, M. A. Santos, Eur. J. Med. Chem. 2015, 100, 257-269. https://doi.org/10.1016/j.ejmech.2015.06.017

[17] A. Sánchez-Recillas, G. Navarrete-Vázquez, S. Hidalgo-Figueroa, M. Y. Rios, M. Ibarra-Barajas, S. Estrada-Soto, Eur. J. Med. Chem. 2014, 77, 400-408. https://doi.org/10.1016/j.ejmech.2014.03.029

[18] F. A. Mir, S. u Rehman, S. H. Khan, Optik 2016, 127, 8361-8366.

https://doi.org/10.1016/j.ijleo.2016.06.039

[19] I. Manolov, C. Maichle-Moessmer, N. Danchev, Eur. J. Med. Chem. 2006, 41, 882-890. https://doi.org/10.1016/j.ejmech.2006.03.007

[20] J. Lehmann, Lancet. 1943, 241, 611-613. https://doi.org/10.1016/s0140-6736(00)43039-4

[21] H. Hussain, J. Hussain, A. Al-Harrasi, K. Krohn, Tetrahedron, 2012, 68, 2553-2578. https://doi.org/10.1016/j.tet.2012.01.035
[22] K. M. Khan, S. Iqbal, M. A. Lodhi, G. M. Maharvi, Z.Ullah, M. I. Choudhary, A. Rahman, S. Preveen, Bioorg. Med. Chem. 2004, 12, 1963-1968. https://doi.org/10.1016/j.bmc.2004.01.010

[23] N. O. Mahmoodi, F. Ghanbari Pirbasti, Z. Jalalifard, J. Chin. Chem. Soc. 2018, 65, 383-394. https://doi.org/10.1002/jccs.201700363

[24] I. Kostova, Curr. Med. Chem. - Anti-Cancer Agents, 2005, 5, 29-46, https://doi.org/10.2174/1568011053352550

[25] A. M. A., Al-Kadasi, G. M. Nazeruddin, Int. J. Chem. Sci. 2012, 10, 324-330

[26] A. I. Koleva, N. I. Petkova-Yankova, R. D. Nikolova, Molecules, 2018, 23, 2810 https://doi.org/10.3390/molecules23112810

[27] S. Qadir, A. A. Dar, K. Z. Khan, Adv. Anal. Chem. 2013, 3, 34-40. https://doi.org/10.5923/j.aac.20130303.03

[28] S. M. Banday, A. Amin, S. Bashir, R. A. Qadri, K. Z. Khanm M. A. Rizvi, Croat. Chem. Acta 2017, 90, 417-480. https://doi.org/10.5562/cca3136

[29] K. Tabatabaeian, M. A. Zanjanchi, M. Mamaghani, A. Dadashi, J. Adv. Chem, 2015, 11, 3532-3539. https://doi.org/10.24297/jac.v11i2.2219

[30] J. N. Sangshetti, N.D. Kokare, D. B. Shinde, Green. Chem. Lett. Rev. 2009, 2, 233-235. https://doi.org/10.1080/17518250903393874

[31] A. Sahar, Z. A. Khan, M. Ahmad, A. F. Zahoor, A. Mansha, A. Iqbal, Trop. J. Pharm. Res. 2017, 16, 203210. https://doi.org/10.4314/tjpr.v16i1.27

[32] H. Kiyani, H. Darbandi, M. Tazari, Jordan J. Chem. 2016, 11, pp. 77-84

[33] A. Tzani, A. Douka, A. Papadopoulos, E. A. Pavlatou, E. Voutsas, A. Detsi, ACS Sustain. Chem. Eng. 2013, 1, 1180-1185. https://doi.org/10.1021/sc4001093

[34] B. Sadeghi, T. Ziya, J. Chem. 2013, 2013, 1-5. https://doi.org/10.1155/2013/179013

[35] Z. Karimi-Jaberi, M. R. Nazarifar, B. Pooladian, Chin. Chem. Lett. 2012, 23, 781-784. https://doi.org/10.1016/j.cclet.2012.05.003

[36] A. N. Nadaf, K. Shivashankar, J. Heterocycl. Chem. 2018, 55, 1375-1381. https://doi.org/10.1002/jhet.3171

[37] M. M. Heravi, S. Sadjadi, N. M. Haj, H. A. Oskooie, F. F. Bamoharram, Catal. Commun. 2009, 10, 1643-1646. https://doi.org/10.1016/j.catcom.2009.04.031

[38] B. Zeynizadeh, M. Gilanizadeh, New J. Chem. 2019, 43, 18794-18804. https://doi.org/10.1039/c9nj04718b 